OPEN ACCESS

Edited by:

Daniela Tropea,

Trinity College, Dublin, Ireland

Reviewed by:

Sushmita Jha,

Indian Institute of Technology

Jodhpur, India

Yingjie Sun,

Harvard University, USA

Amul J. Sakharkar,

Savitribai Phule Pune University, India

*Correspondence:

Zhicheng Gong

gongzhicheng2013@163.com

tThese authors have contributed equally to this work.

Received: 05 July 2016 Accepted: 15 February 2017 Published: 28 February 2017

Citation:

Yan Y, Xu Z, Li Z, Sun L and Gong Z (2017) An Insight into the Increasing Role of LncRNAs in the Pathogenesis

of Gliomas.

Front. Mol. Neurosci. 10:53. doi: 10.3389/fnmol.2017.00053

\section{An Insight into the Increasing Role of LncRNAs in the Pathogenesis of Gliomas}

\author{
Yuanliang Yan ${ }^{1,2+}$, Zhijie Xüt, Zhi Li ${ }^{4}$, Lunquan Sun ${ }^{4}$ and Zhicheng Gong ${ }^{1,2 *}$ \\ 1 Department of Pharmacy, Xiangya Hospital, Central South University, Changsha, China, ${ }^{2}$ Institute of Hospital Pharmacy, \\ Central South University, Changsha, China, ${ }^{3}$ Department of Pathology, Xiangya Hospital, Central South University, \\ Changsha, China, ${ }^{4}$ Center for Molecular Medicine, Xiangya Hospital, Key Laboratory of Molecular Radiation Oncology of \\ Hunan Province, Central South University, Changsha, China
}

Long non-coding RNAs (LncRNAs) are essential epigenetic regulators with critical roles in tumor initiation and malignant progression. However, the roles and mechanisms of aberrantly expressed IncRNAs in the pathogenesis of gliomas are not fully understood. With the development of deep sequencing analyses, an extensive amount of functional non-coding RNAs has been discovered in glioma tissues and cell lines. Additionally, the contributions of several IncRNAs, such as Hox transcript antisense intergenic RNA, H19 and Colorectal neoplasia differentially expressed, previously reported to be involved in other pathogenesis and processes to the oncogenesis of glioblastoma are currently addressed. Thus, IncRNAs detected in tumor tissues could serve as candidate diagnostic biomarkers and therapeutic targets for gliomas. To understand the potential function of IncRNAs in gliomas, in this review, we briefly describe the profile of IncRNAs in human glioma research and therapy. Then, we discuss the individual IncRNA that has been under intensive investigation in glioma research, and the focus is its mechanism and clinical implication.

Keywords: glioma, IncRNAs, diagnostic biomarkers, therapeutic targets, therapy

\section{INTRODUCTION}

Glioblastoma (GBM) is the most common primary intracranial tumor, with varying malignancy grades and histological subtypes. Although relatively rare in occurrence, GBM frequently causes mortality and morbidity (Ostrom et al., 2014; Bian et al., 2015), and its median survival time is only 12-14 months after initial diagnosis (Stetson et al., 2016). The current standard therapy for GBM is concomitant radiochemotherapy following maximal surgical tumor resection. However, aggressive growth and recurrence frequently follows after the optimal treatment (Penaranda Fajardo et al., 2016). It is conceivable that complicated signaling pathways and related molecular events underlie the development of gliomas. Consequently, investigations exploring the accurate molecular mechanisms and reliable therapeutic targets for GBM have drawn extensive attention and provided a hopeful prospect for GBM treatment (Kitambi et al., 2014; Furnari et al., 2015).

Abbreviations: ADAMTS, a disintegrin and metalloproteinase with thrombospondin motif; BTB, blood-tumor barrier; CASC2, cancer susceptibility candidate 2; CRNDE, colorectal neoplasia differentially expressed; CSCs, cancer stem cells; GAS5, growth arrest-specific 5; GBM, glioblastoma; HOTAIR, Hox transcript antisense intergenic RNA; HULC, highly up-regulated in liver cancer; lncRNAs, long non-coding RNAs; NEAT1/2, nuclear enriched abundant transcript 1/2; TMZ, temozolomide; TUG1, taurine up-regulated gene 1; XIST, X-inactive specific transcript. 
Recently, epigenetic regulation has also drawn remarkable attention, particularly in terms of lncRNAs, which are indispensable for the regulation of cellular processes. LncRNAs are transcripts of more than 200 nucleotides without functional protein-coding ability in a conventional way (Quinn and Chang, 2016). Intriguingly, their coding and translation potential have been reported; they may act as a repository for the synthesis of small polypeptides with interesting biological activity (Cohen, 2014; Ruiz-Orera et al., 2014). LncRNAs can be grouped into five non-exclusive categories according to their genomic location. The subcellular localization is a good indication of the putative function of a lncRNA (Schmitz et al., 2016) (Figure 1). For the past three decades, lncRNAs have been found to regulate gene expression during both biological and pathological processes (Fatica and Bozzoni, 2014). For instance, lncRNAs can work as cellular "address codes," which allows protein complexes to be transferred to the appropriate locations on chromosomes and results in consequent activation or deactivation (Batista and Chang, 2013). Mechanistically, in contrast to small interfering RNAs (siRNAs) and microRNAs, lncRNAs can fold into higher order structures to provide much greater potential for target recognition, which facilitates chromatin remodeling as well as transcriptional and post-transcriptional regulation (Mercer and Mattick, 2013; Sahu et al., 2015).

In accordance with their significant roles in normal biological processes, lncRNAs have been implicated in the oncogenesis of gliomas and are increasingly being considered potential therapeutic targets (Ma et al., 2016; Schmitt and Chang, 2016). For example, the well-studied HOTAIR, a lncRNA highly expressed in breast cancer that participates mainly in the chromatin remodeling process, was found to be associated with the biogenesis, development and differentiation of gliomas (Bian et al., 2016). Furthermore, some newly discovered lncRNAs have been found in glioma tissue and cell lines, such as lncRNA ASLNC22381and KIAA0495 (Trojan et al., 2003; Zhang X.Q. et al., 2013, 2015). Through investigating the lncRNAs in tissue specimens for their expression stability in human gliomas and normal brain, Kraus et al. (2015) identified four lncRNAs (HOXA6as, H19 upstream conserved 1 and 2, Zfhx2as and BC200) with stable expression levels in gliomas compared with normal brain. Collectively, these lncRNAs have gained value for clinical purposes as novel biomarkers, but despite this great potential, many issues remain in this rapidly growing field. Here, we summarize the most up-to-date findings regarding how lncRNAs are regulated at the molecular level and their implications in the areas of glioma research and therapy.

\section{PROFILE OF LNCRNAS IN HUMAN GLIOMA RESEARCH AND THERAPY}

Recent studies in the large-scale analyses of full-length cDNA sequences have discovered many lncRNAs as key players of cell differentiation, immune responses, tumorigenesis, and other biological processes (Wakamatsu et al., 2009; Fujimoto et al., 2016; Wang J. et al., 2016). The Cancer Genome Atlas (TCGA), an ambitious and successful cancer genomics project, generates large-scale multi-dimensional genomic datasets covering over 20 malignancies, providing valuable insights into the underlying genetic and genomic alteration of cancer (Wang Z. et al., 2016). Deep sequencing studies, including large consortia, such as TCGA, have identified numerous tumor-specific mutations not only in protein-coding sequences, but also in noncoding sequences, which have proven to be an important component hidden in the "dark matter" of the genome. These cancer-associated mutations within non-coding RNA, including lncRNAs, can affect gene regulation in the pathogenesis and development of gliomas (Ramos et al., 2016; Diederichs et al., 2016). Differentially expressed lncRNAs in gliomas have been widely analyzed using human glioma tissues and cell lines (Table 1). These studies indicated that abnormal lncRNAs plays critical roles in the development and progression of gliomas.

The lncRNA profile in clinical specimens reveals their potential roles in GBM pathogenesis. Using microarrays to analyze the tissues of GBM patients and age-matched normal donors, Han et al. (2012) found the lncRNA expression profile in GBM tissue is significantly altered. In GBM tissue, 654 lncRNAs are up-regulated (fold change $\geq 4.0$ ), and 654 are down-regulated (fold change $\leq 0.25$ ). Among the up-regulated lncRNAs, ASLNC22381 and ASLNC2081 are likely to serve as the key elements in the regulation of glioma signaling pathways. Target gene-related pathway analysis indicated that ASLNC22381 and ASLNC20819 may play important roles via their target insulin-like growth factor 1 (IGF-1) genes, which has been thought to be a positive risk factor for human glioma development (Rohrmann et al., 2011). In addition, applying the Affymetrix HG-U133 Plus 2.0 array, Zhang X. et al. (2012) revealed that in tumors relative to normal brain tissues, lncRNA C21orf131-B, MEG3, and RFPL1S are down-regulated, while HOTAIRM1 (HOX antisense intergenic RNA myeloid 1) and CRNDE are comparably up-regulated. Of note, these lncRNA expression patterns show a close correlation with malignancy grade and histological differentiation in human gliomas (Zhang X. et al., 2012). The same group later identified a set of six lncRNAs in 107 GBM patients, including KIAA0495, PART1, MGC21881, MIAT, GAS5, and PAR5, that are significantly associated with overall survival. The prognostic value of this six-lncRNA signature is independent of the methylation status of O-6-methylguanine-DNA methyltransferase (MGMT) promoter, which can promote the treatment resistance of glioma cells to alkylating agent chemotherapy (Zhang X.Q. et al., 2013; Wick et al., 2014). Moreover, based on the lncRNA expression profiles, Li R. et al. (2014) identified three novel molecular subtypes (named LncR1, LncR2 and LncR3) in gliomas. Survival analysis indicated that the LncR1 subtype has the poorest prognosis, while the LncR3 subtype shows the best overall survival rate (Li R. et al., 2014). Another study on lncRNA and mRNA interactions revealed that lncRNAs, such as Hox cluster-associated lncRNAs, can modulate a list of genes participating in the pathogenesis of GBM (Yan et al., 2015). In addition, the expression profiles analysis in recurrent gliomas compared with primary gliomas identified abundant differentially expressed lncRNAs, such as 


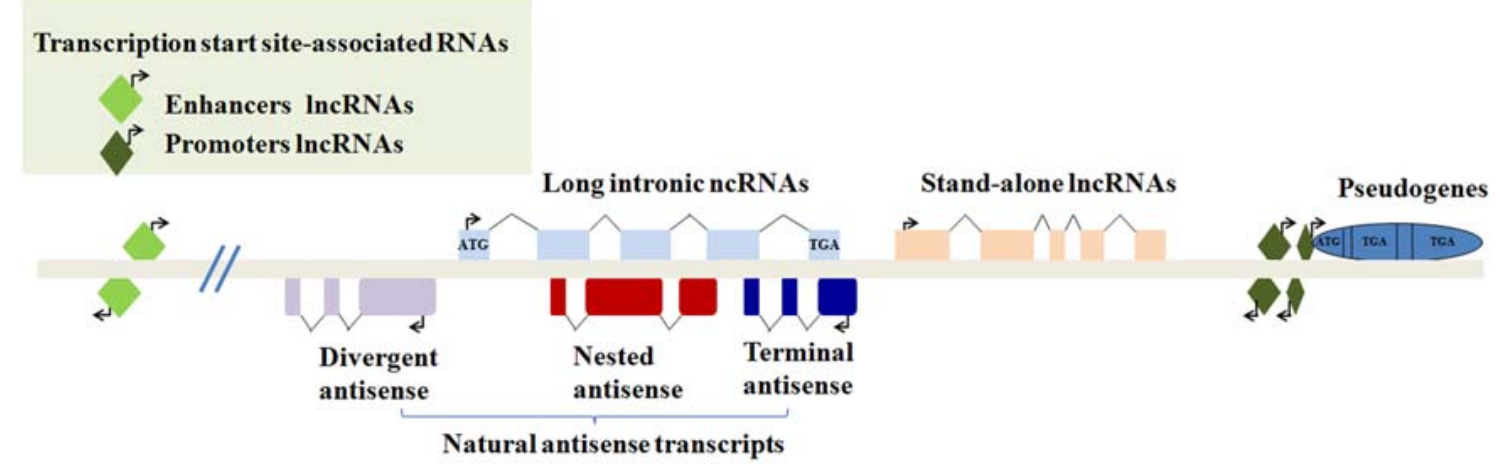

FIGURE 1 | Classification of IncRNAs according to their genomic location. (1) Transcription start site-associated RNAs may be transcribed from enhancers or promoters. (2) Long intronic ncRNAs may be transcribed from introns of other genes. (3) Natural antisense transcripts contain divergent antisense, nested antisense or terminal antisense. (4) Stand-alone transcription units. (5) Some transcribed pseudogenes.

H19, CRNDE, and HOTAIRM1. These results imply that the future studies of specific expressed lncRNAs would help elucidate the mechanism of glioma recurrence at the genetic level and identify effective therapeutic targets for glioma patients (Chen et al., 2015).

Additionally, in vitro studies have strongly suggested that the altered expression of lncRNAs during genome mutation or genotoxic stress is involved in multiple neuro-oncological disorder-associated cellular processes. Isocitrate dehydrogenase 1 (IDH1) mutations have been shown to be an important prognostic marker for patients with gliomas (Cai et al., 2016; Wang P.F. et al., 2016). LncRNA profiling between gliomas with or without IDH1 mutations show significantly altered gene expressions in astrocytic and oligodendroglial tumors. Among the differential lncRNAs, KIAA0495, LOC254559 and LOC255130 have a close correlation with clinical outcomes in IDH1-mutant patients. Moreover, these three IDH1 mutation-associated lncRNAs participate in multiple tumor-associated cellular biological behaviors, including cell proliferation, apoptosis and metastasis (Zhang X.Q. et al., 2015). In addition, after treatment with DNA damaging reagents, such as doxorubicin and resveratrol, specific candidate lncRNAs (MEG3, ST7OT1, TUG1, BC200 and MIR155HG) are detected in human glioma cell lines (U251 and U87). During apoptosis induced by both reagents, MEG3 and ST7OT1 are up-regulated in both cell lines. Instead, when necrosis is induced with a high dose of doxorubicin, TUG1, BC200 and MIR155HG are significantly down-regulated (Liu Q. et al., 2015). As NEAT2 (nuclear-enriched abundant transcript 2), also known as MALAT1 (metastasis-associated lung adenocarcinoma transcript 1), is a highly conserved lncRNA associated with the metastatic potential of tumor cells, Han et al. (2016a) found that the knockdown of NEAT2 by RNA interference could promote the invasion and proliferation of glioma cells. Concomitantly, the apoptosis rate of the glioma cell lines is shown to dramatically increase (Han et al., 2016a; Xiang et al., 2016). Over all, these results indicate that an investigation into the abnormal expression profiles of lncRNAs may help in the understanding of oncogenesis and identify novel potential treatment targets in glioma research and therapy.

Accumulating evidence indicates that a rare population of self-renewing cells, called tumorigenic CSCs, is responsible for tumor formation and therapeutic resistance in gliomas (Lathia et al., 2015). Studies have indicated that lncRNAs are involved in several biological processes in CSCs (Li Y. et al., 2015). A large-scale expression study of functional ultra-conserved (uc) ncRNAs showed that the uc.283 lncRNA, a 277 nucleotide-long sequence located at ultra-conserved regions (UCRs) of human genes, is highly specific for pluripotent stem cells, as well as some solid cancers, particularly gliomas (Galasso et al., 2014). Moreover, Han et al. (2016b) found that the down-regulation of NEAT2 suppresses the expression of stemness markers Sox2 and Nestin, and further promotes cell proliferation by regulating the ERK/MAPK (extracellular signal-regulated kinase/mitogenactivated protein kinase) signaling axis in the glioma stem cell line SHG139. Furthermore, the knockdown of the lncRNA XIST could exert tumor-suppressive effects in human GBM stem cells by up-regulating miR-152 (Yao et al., 2015). In addition, as the gene enhancer of zeste homolog 2 (EZH2) serves as an oncogene and is required for cancer stem cell maintenance, the inhibition of EZH2 by lncRNAs can effectively promote the therapeutic sensitivity in gliomas (van Vlerken et al., 2013; Yin et al., 2016). Based on these observations, much more attention should be paid on the regulation of lncRNAs in the maintenance of glioma stem cells (GSCs), a decisive event occurring in the development of gliomas.

\section{ABERRANTLY EXPRESSED LNCRNAS AND THEIR IMPLICATIONS IN HUMAN GLIOMAS}

The differential expression patterns of lncRNAs between tumor and normal tissues, along with the expression discrepancies in tumors with different clinical features, provide the possibility that lncRNAs act as diagnostic, prognostic biomarkers and pharmaceutical targets in gliomas. Although an increasing 


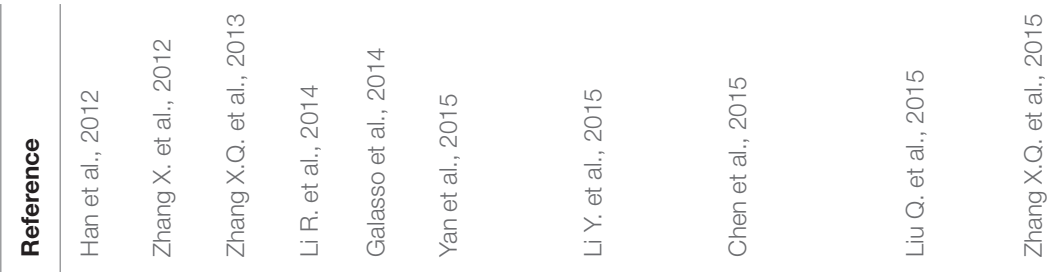

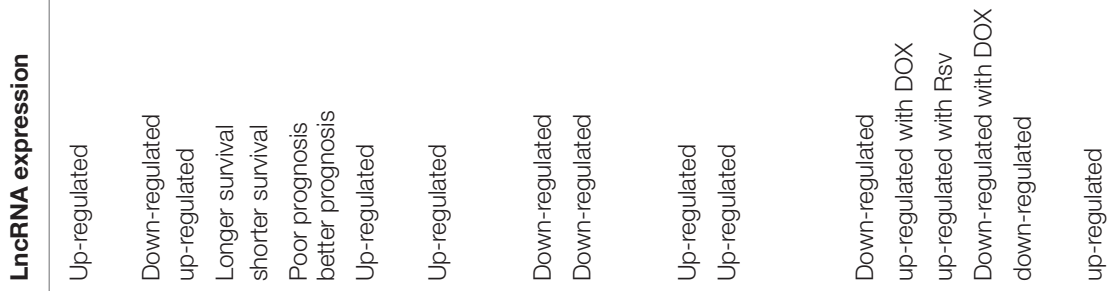
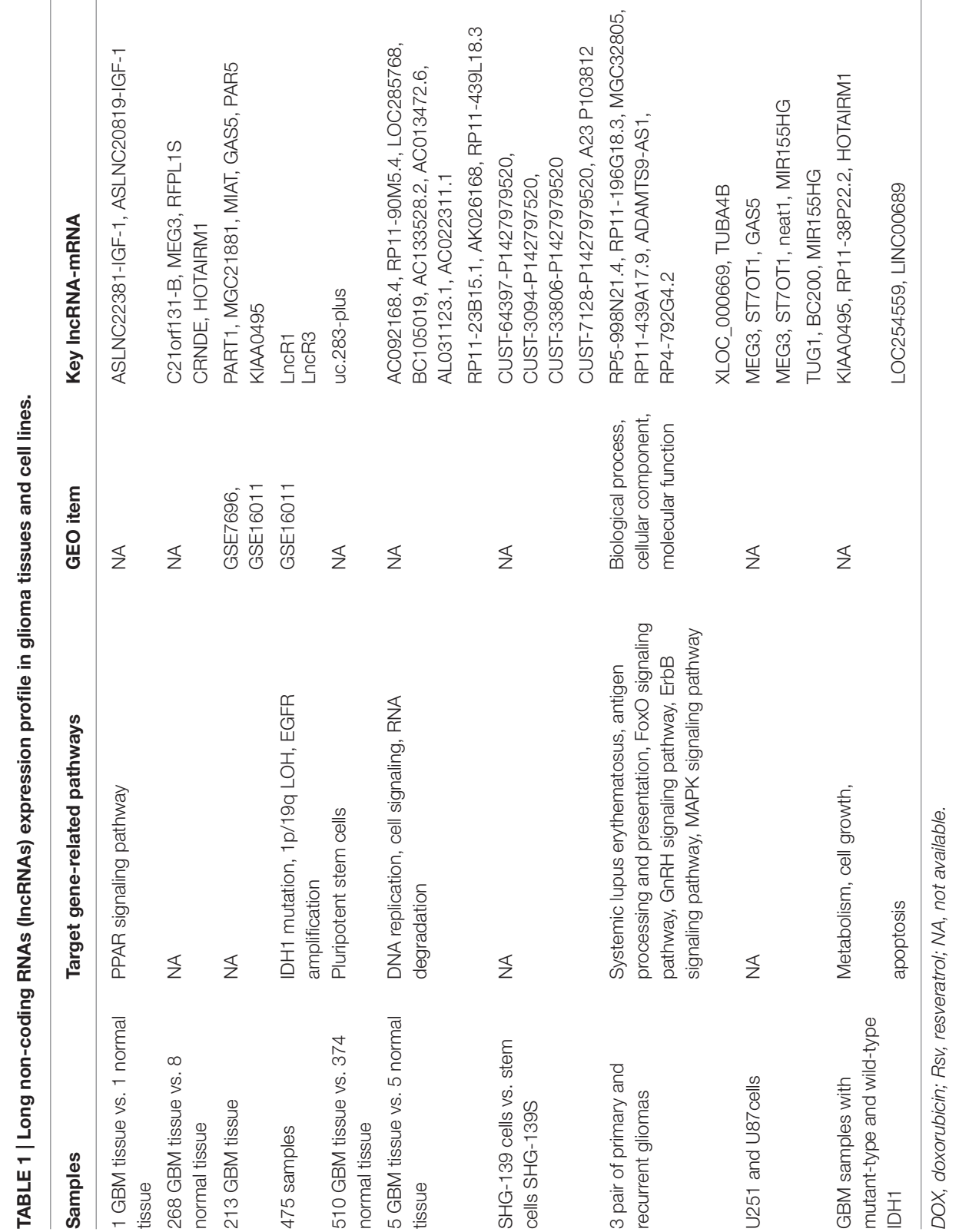
number of lncRNAs are being characterized, their detailed mechanisms are still not completely elucidated. In this regard, recent studies have demonstrated that lncRNAs in gliomas can serve as molecular decoys, which move proteins or RNAs away from a specific location, like a "sponge" to miRNAs (e.g., HOTAIR/miR-326, CASC2/miR-21, XIST/miR-152, and Gas5/miR-222). Additionally, other investigations demonstrate lncRNAs can function as molecular signaling mediators, which modulate the expression of a certain set of genes (e.g., H19/CD133 and NEAT2/MMP2) (Figure 2). To provide an exhaustive description of the rapid development in this field, the molecular mechanisms and potential functions of several representative lncRNAs in gliomas will be discussed in the following sections.

\section{LncRNA HOTAIR}

Long non-coding RNA HOTAIR, transcribed from the antisense strand of the homeobox $\mathrm{C}$ (HOXC) gene locus in chromosome 12 , is involved in the regulation of specific gene transcription. A study by Tsai et al. (2010) demonstrated that HOTAIR regulates gene expression by interacting with polycomb repressive complex 2 (PRC2) and lysine-specific demethylase 1A (LSD1). The $5^{\prime}$ - and $3^{\prime}$-domains of HOTAIR can bind to the PRC2 and LSD1/CoREST/REST complex, respectively. Serving as a scaffold, HOTAIR can tether two distinct complexes together and recruit specific histone modification enzymes, thereby resulting in $\mathrm{H} 3 \mathrm{~K} 27$ methylation and $\mathrm{H} 3 \mathrm{~K} 4$ demethylation and ultimately gene silencing (Tsai et al., 2010). In addition, HOTAIR could also serve as an inducer of ubiquitin-mediated proteolysis to control protein levels. HOTAIR facilitates the ubiquitination of Ataxin-1 through E3 ubiquitin ligases Dzip3, Snurportin-1, and Mex3b to further accelerate their degradation. Through the rapid decay of targets Ataxin-1 and Snurportin-1, HOTAIR can prevent cellular premature senescence (Yoon et al., 2013). In addition, aberrant HOTAIR expression has been extensively revealed to correlate with cancer metastasis and is characterized as a negative prognostic factor for cancer patients (Cai et al., 2014; Wu et al., 2014).

Hox transcript antisense intergenic RNA expression is upregulated in glioma tissues and cell lines, and can serve as a potential biomarker or therapeutic target for human gliomas (Kiang et al., 2015; Zhou et al., 2015) (Figure 3). Recent studies have indicated that HOTAIR expression is a critical regulator of cell cycle progression in gliomas (Zhang J.X. et al., 2013). HOTAIR regulates cell cycle progression predominantly via the HOTAIR $5^{\prime}$-domain-PRC2 axis, which is EZH2 (predominant PRC2 complex component)-dependent in GBM cells (Zhang K. et al., 2015). In addition, bromodomain and extraterminal (BET) domain proteins are required for GBM cell proliferation. BET protein inhibitors can reduce the proliferation of gliomas, in part, through the induction of the cyclin-dependent kinase inhibitor $\mathrm{p} 21^{\mathrm{Cip} 1}$ in vitro and in vivo (Pastori et al., 2014). Pastori et al. (2014) found that the bromodomain protein BRD4 could directly control HOTAIR expression by binding to its promoter. The overexpression of HOTAIR in conjunction with the BET

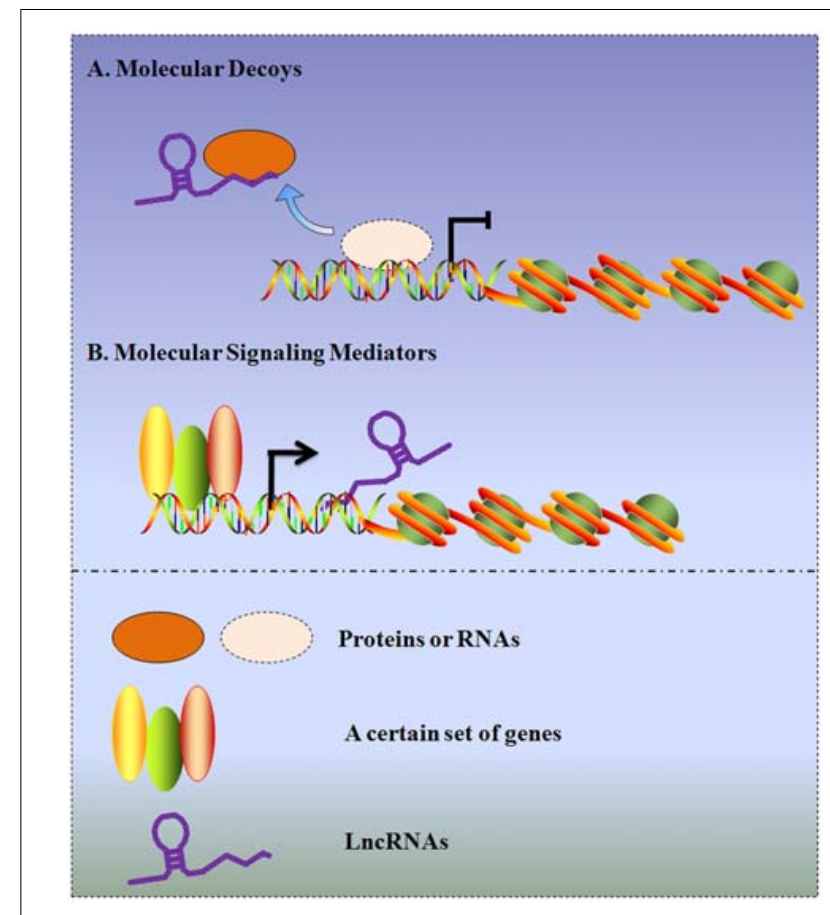

FIGURE 2 | Schematic diagram of the two archetypes of IncRNA mechanisms in gliomas. (A) LncRNAs in gliomas can serve as molecular decoys, which take proteins or RNAs away from a specific location.

(B) LncRNAs in gliomas can serve as molecular signaling mediators, which modulate the expression of a certain set of genes.

protein inhibitor I-BET151 abolishes the anti-proliferative activity of the BET bromodomain inhibitor (Pastori et al., 2015). Furthermore, the HOTAIR-miRNA axis has an important role in malignant biological behaviors of human glioma. Ke et al. (2015) found that fibroblast growth factor 1 (FGF1) mediates oncogenic effects by activating the PI3K/AKT and MEK $1 / 2$ pathways. HOTAIR, one target of miR-326, has been confirmed to down-regulatemiR-326; then, it exerts its tumor-suppressive activities by reducing the expression of FGF1 (Ke et al., 2015). Similarly, HOTAIR can act as an endogenous "sponge" of miR-141, thereby promoting the promoter methylation of miR-141 by DNA methyltransferase 1 (DNMT1) in glioma cells. Then, the hypermethylated miR141 can repress the expression of the spindle and kinetochore associated complex subunit 2 (SKA2), which results in a significant increase in tumor growth (Bian et al., 2016). Collectively, these results suggest that HOTAIR may potentiate glioma development in many facets; thus, it is worthy of further investigation.

\section{LncRNA H19}

Long non-coding RNA H19, produced from the imprinted gene $\mathrm{H} 19$, is one of the most highly conserved transcripts involved in mammalian development. Studies have also demonstrated that $\mathrm{H} 19$ could potentially serve as an oncogenic lncRNA in different types of cancers, including gliomas (Kiang et al., 2015; Chen et al., 2016). Mechanistically, the product of the 


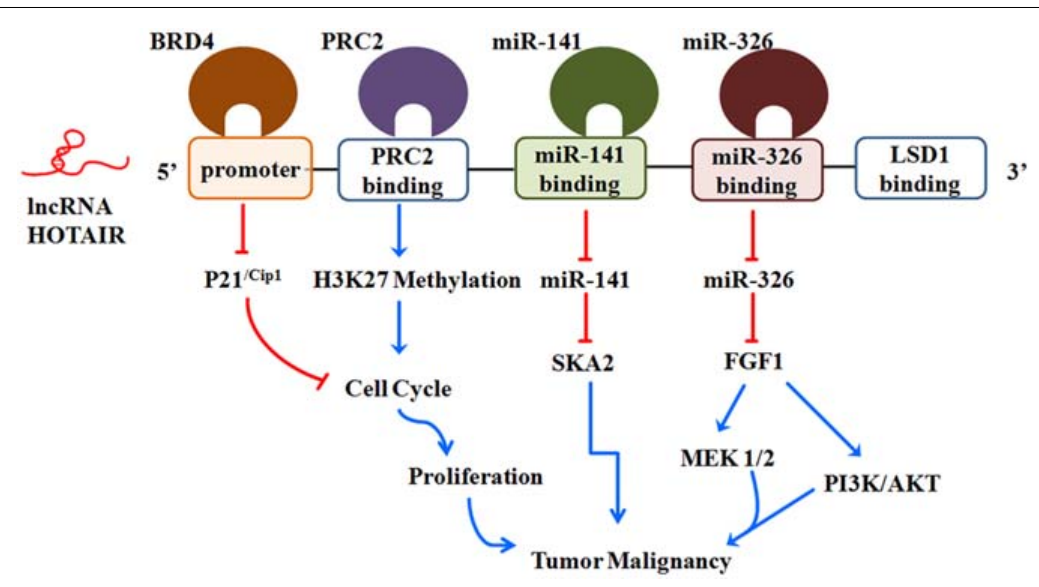

FIGURE 3 | Roles of IncRNA HOTAIR in glioma malignancy. See text for detailed discussion.

MYC oncogene, c-Myc, induces the expression of the H19 non-coding RNA, thereby potentiating gliomagenesis (BarsyteLovejoy et al., 2006). Furthermore, serving as a miRNA precursor, H19 could modulate glioma progression by generating miR- 675 . The oncogenic function of H19/miR-675 is dependent on the expression of cancer-associated cadherin 13 (CDH13), which is the direct target of miR-675 (Shi et al., 2014). Li C. et al. (2015) found that miRNA-675, which is derived from the first exon of H19, could regulate the immoderate proliferation and migration of glioma cell lines by inhibiting the expression of CDK6, which is a pivotal regulator of the cell cycle and involved in glioma development (Rader et al., 2013; Sherr et al., 2016). These findings agree with another study showing that H19 overexpression can promote the cell-cycle progression of cancer cells (Berteaux et al., 2005). Moreover, the knockdown of H19 by siRNA displays higher therapy efficiency when induced by the chemotherapy drug TMZ in GBM cells (Li W. et al., 2016). Thus, LncRNA H19 could be increasingly recognized as a potential target for glioma treatment.

Accumulating evidence has identified that tumorigenic CSCs, with self-renewing capability, contribute to tumor initiation and therapeutic resistance (Lathia et al., 2015). Intriguingly, H19 overexpression could maintain the stem cell properties of GBM cells. Li W. et al. (2016) found that the markers of CSCs, including CD133, NANOG, Oct4, and Sox2, are significantly down-regulated in H19-deficient cells. This conclusion was further confirmed by Jiang et al. (2016), who found that the increased level of H19 promotes invasion, angiogenesis, and stemness of GBM cells. H19 is significantly overexpressed in CD133-positive GBM cells, and higher H19 expression levels are associated with increased tumor growth (Jiang et al., 2016). In spite of the critical role of H19 in the maintenance of glioma stemness, its exact mechanism is still unclear and needs to be further investigated.

\section{LncRNA CRNDE}

Colorectal neoplasia differentially expressed was initially identified by Derrien et al. (2012) as a putative non-coding
RNA; it is highly expressed in developmental neurobiology and neuropathology. Studies have found that CRNDE expression is also elevated in many colorectal cancers and brain cancers, such as GBM, astroblastomas, and astrocytomas (Ellis et al., 2012; Kiang et al., 2015). Of note, among the 129 lncRNAs differentially expressed in glioma tissues, CRNDE is consistently identified as the most up-regulated lncRNA by 32-fold up (Zhang X. et al., 2012).

Colorectal neoplasia differentially expressed potentiates glioma development possibly by maintaining the stemness of the tumor cells, as it functions in neural precursors (Ellis et al., 2012; Watkins and Sontheimer, 2012). In support of this notion, a previous study by Zheng J. et al. (2015) demonstrated a direct link between the overexpression of CRNDE and GSCs. Mechanistically, CRNDE could negatively regulate miR-186 and depress the expression of the downstream target genes XIAP (X-linked inhibitor of apoptosis) and PAK7 [p21 protein (Cdc42/Rac)-activated kinase 7], thus contributing to the malignant characteristics of human GSCs (Zheng J. et al., 2015). In addition to these observations, Wang Y. et al. (2015) showed that the overexpression of the CRNDE transcript promotes glioma cell growth in vitro and in vivo through mammalian target of rapamycin (mTOR) signaling. Intriguingly, epigenetic modifications, including histone acetylation in the promoter region, can also promote CRNDE expression (Wang Y. et al., 2015). More recently, CRNDE was reported to promote malignant behavior by attenuating the miR-384/PIWIL4 (piwilike RNA-mediated gene silencing 4) axis. Briefly, CRNDE knockdown can decrease the protein level of PIWIL4, a target of miR-384, which leads to glioma regression in vivo (Zheng J. et al., 2016). Overall, these results revealed that CRNDE could potentiate glioma via multiple signaling pathways and may be a promising novel therapeutic target for glioma therapy.

\section{LncRNA CASC2}

Cancer susceptibility candidate 2, located at chromosome 10q26, is a lncRNA originally identified as a tumor suppressor gene in endometrial cancer. CASC2 consists of three alternatively 
spliced transcript isoforms, CASC2a, CASC2b and CASC2c, which contain identical first three exons and diverse downstream exons (Zhao et al., 2014). CASC2a expression is down-regulated at the transcription level in endometrial cancer. Baldinu et al. (2007) revealed that the exogenous expression of CASC2a in undifferentiated endometrial cancer cells significantly inhibits the clonal growth. Using a positional candidate approach, 7\% CASC2a mutations in tumor DNA from 44 endometrial cancer patients were identified (Baldinu et al., 2004), suggesting that inactivation of CASC2a might probably be due to mechanisms different from genetic alterations. In non-small cell lung cancer (NSCLC) tissues and cell lines, He X. et al. (2016)) reported that CASC2 expression is involved in the development and progression of NSCLC. However, little is known about the role and function of CASC2 in human gliomas.

Recently, Wang P. et al. (2015) reported that CASC2 expression is decreased in glioma tissues as well as glioma cell lines (U251 and U87). Consistent with previous studies in other tumors, the overexpression of CASC2 could inhibit the malignancy of glioma cells through an arrest of proliferation and migration, correspondingly promoting cellular apoptosis. RIP and RNA pull-down assays confirmed that the tumor suppressive role of CASC2 is mainly mediated via the down-regulation of miR-21, one potential direct target of CASC2, in a sequencespecific manner (Wang P. et al., 2015). A growing body of literature has shown that miR-21 serves as an oncogene, and the inhibition of miR-21 is a novel therapeutic strategy for specific and effective action against gliomas (Harmalkar et al., 2015; Belter et al., 2016). Mechanistically, miR-21 promotes gliomagenesis by regulating multiple oncogenesis-related processes, including proliferation, apoptosis, migration and invasion. Therefore, targeting the CASC2-miR-21 axis may be an effective strategy for the treatment of malignant gliomas.

\section{LncRNA XIST}

$\mathrm{X}$-chromosome inactivation (XCI) ensures dosage compensation between the sexes in mammals and is a paradigm for allelespecific gene expression on a chromosome-wide scale. The lncRNA XIST, a product of the XIST gene, is located within the $500 \mathrm{~kb}$ stretch of XCI DNA at Xq13, which is known as the $\mathrm{X}$-inactivation center (XIC); XIST is the master regulator of X chromosome inactivation in mammals (Furlan and Rougeulle, 2016; Maduro et al., 2016). The current model proposes that XIST induces epigenetic silencing of multiple genes by recruiting the chromatin modifier, the PRC2 complex, to the XIC (Goodrich et al., 2016). With the help of the highaffinity RNA-binding protein ATRX (alpha thalassemia/mental retardation syndrome X-linked), a growing number of XIST RNAs accumulate and are tethered to the $\mathrm{X}$ chromosome. Afterward, the XIST RNA spreads and forms a RNA "cloud" coating the XIC in cis. To recruit PRC2, the XIST RNA first associates with approximately 150 intense PRC2 binding sites (CpG islands), followed by its association with 3,000-4,000 moderate-strength binding sites of PRC2. Finally, XIST RNA spreads to both gene-rich and poor regions in distinct stagespecific forms on the X chromosome (Simon et al., 2013; Sarma et al., 2014).
$\mathrm{X}$-inactive specific transcript has been found to be dysregulated in a variety of human cancers (Yildirim et al., 2013; Tantai et al., 2015). Specifically, a recent study showed that XIST expression is abnormally up-regulated in glioma tissues and GSCs. The knockdown of XIST by short-hairpin RNA exerts a tumor suppressive function in GSCs. Furthermore, as XIST and miR-152 may form a reciprocal repression feedback loop and are located in the same RNA induced silencing complex (RISC), miR-152 can mediate the promotion of GSCs by XIST (Yao et al., 2015). In addition, XIST can inhibit hepatoma cell proliferation and metastasis by targeting miR-92b (Zhuang et al., 2016). Moreover, XIST has been identified to directly bind tomiR-210 (Fasanaro et al., 2009). Consistently, other miRNAs, such as miR-92b and miR-210, may also regulate the expression of XIST in gliomas. Altogether, further studies should focus on the XIST-miRNA axis in glioma research and treatment.

\section{LncRNA TUG1}

Taurine up-regulated gene 1 , a $7.1 \mathrm{~kb}$ lncRNA located at chromosome 22q12, is a cancer-related lncRNA in some tumors, including NSCLC (Zhang et al., 2014), bladder cancer (Tan et al., 2015) and gliomas (Li J. et al., 2016). TUG1 was first identified in a genomic screen for genes differentially regulated by taurine in developing mouse retinal cells. Furthermore, TUG1 is found to play crucial roles in the formation of photoreceptors and retinal development (Young et al., 2005).

Recent investigations have reported that in human glioma cell lines, TUG1 is down-regulated, in response to necrosis induced by a high dose of DOX (Liu Q. et al., 2015). Li J. et al. (2016) showed that TUG1 acts as a tumor suppressor in glioma tumorigenesis, and is negative correlated with glioma grade, tumor size, and overall survival. Further studies via gainand loss-of-function assays revealed that TUG1 induces glioma cell apoptosis through caspases-mediated intrinsic pathways, rather than the Bcl-2-mediated anti-apoptotic pathway (Li J. et al., 2016). However, the precise mechanism of TUG1 in cell proliferation, as well as invasion, in glioma development is still unclear. The BTB limits the effect of conventional chemotherapy by restricting drug delivery to brain tumor tissues (Hendricks et al., 2015). Using a co-culture assay with glioma and endothelial cells, Cai et al. (2015) revealed that the knockdown of TUG1 could reduce tight junction protein expression in endothelial cells by down-regulating heat shock transcription factor 2 (HSF2), the target of miR-144, increasing BTB permeability of chemotherapeutic agents. Thus, there may be potential role of TUG1 in anti-glioma therapy, and BTB function may represent a useful therapeutic intervention strategy in the future.

\section{LncRNA NEAT1/2}

Nuclear enriched abundant transcript 1 (NEAT1) is an essential lncRNA for the formation of paraspeckles, which are nuclear bodies named for their close proximity to nuclear speckles (Yu and Shan, 2016). NEAT1 is an unusual RNA polymerase II (pol II) transcript that lacks introns, and it is widely expressed in many types of mammalian cells (Naganuma and Hirose, 2013). NEAT2/MALAT1 is a highly conserved lncRNA associated with 
tumorigenesis and plays a prognostic role in various cancers (Wei and Niu, 2015).

Up to date, IncRNAs have been demonstrated to be involved in the DNA damage response, thus contributing to the process of cellular defense against genotoxic agents (Zhang and Peng, 2015). Upon treatment with the DNA damage-inducing agent resveratrol, NEAT1 is up-regulated in the glioma cell lines U251 and U87 (Liu Q. et al., 2015). An increase in NEAT1 expression has also been reported in human glioma tissues compared with non-cancerous brain tissues. NEAT1 promotes glioma pathogenesis by regulating glioma cell proliferation, invasion, and migration. Zhen et al. (2016) demonstrated that functioning as a molecular sponge for miR-449b-5p, NEAT1 could up-regulate the expression of c-Met, a direct target of miR-449b-5p, thus promoting glioma oncogenesis. Furthermore, clinical investigations revealed that aberrant NEAT1 expression is negatively associated with clinical outcome in high-grade glioma patients (He C. et al., 2016).

Recent works have illustrated the tumor-suppressive role of NEAT2 in the development of glioma cells. NEAT2 expression is lower in glioma tissues than in normal brain tissues. Mechanistically, NEAT2 inhibits the proliferation and invasion of glioma cells (U87 and U251) by inactivating ERK/MAPK signaling and down-regulating MMP2 (matrix metalloproteinase 2; Han et al., 2016a). In contrast, Xiang et al. (2016) showed an opposite role of NEAT2 in gliomas. According to their observations, NEAT2 expression is significantly increased in glioma tissues, as well as in U87 and U251 cells (Xiang et al., 2016). Remarkably, GSCs of the U87, SHG44 and SHG139 cell lines expressed higher levels of NEAT2 than their parental lines (Han et al., 2016a). In addition, Han et al. (2016b) found that the down-regulation of NEAT2 suppresses the expression of stemness markers Sox 2 and Nestin in SHG139S cells, while NEAT2 down-regulation promotes the proliferation of SHG139S cells. Therefore, NEAT2 plays a complex role in gliomagenesis as both a positive and a negative regulator, possibly based on its specific cellular context.

\section{LncRNA GAS5}

Growth arrest-specific 5, localized at chromosome 1q25.1, could transcribe a tumor-suppressive lncRNA in human cancers. To date, GAS5 has been considered to act as a "riborepressor" or "miRNA sponge" that modulates the transcriptional activity of cancer-associated genes (Kino et al., 2010; Zhang Z. et al., 2013). Recent studies have reported that GAS5 negatively regulates the growth of cancer cell lines in vitro and in vivo, including gliomas (Pickard and Williams, 2015). GAS5 exerts complementary effects on cell proliferation (inhibitory) and apoptosis (stimulatory), and taken together, these cellular mechanisms likely form the basis of its tumor-suppression action (Yin et al., 2014; Shi X. et al., 2015). Mechanistically, the up-regulation of Gas5 increases the expression of tumor suppressor bmf (Bcl-2-modifying factor) and Plexin $\mathrm{C} 1$ via directly reducing the expression of miR-222 (Zhao X. et al., 2015). In addition, the overexpression of GAS5 could enhance the cellular response to erlotinib, a tyrosine kinase inhibitor used as a second line treatment for glioma (Garcia-Claver et al., 2013).
The induction of GAS5 is apparently detected during DOXinduced apoptosis in human glioma cell lines (Liu Q. et al., 2015). The above examples suggest that GAS5 may be used as diagnostic markers or therapeutic targets for gliomas, but much work needs to be done before such applications become clinically practical.

\section{LncRNA ADAMTS9-AS2}

The ADAMTS family has been implicated in essential physiological processes, such as angiogenesis and organ development (Ho et al., 2016). ADAMTS9-AS2 is the antisense transcript of ADAMTS9, a member of the ADAMTS family. Walsh et al. (2016) pointed that ADAMTS9-AS2 plays a critical role in epigenetic regulation, affecting early stage digit development. Recently, the ADAMTS9-AS2 locus has been revealed as a potential therapeutic target and prognostic marker in gliomas. ADAMTS9-AS2 serves as a tumor suppressor, which is significantly down-regulated in glioma tissues, and its expression is negatively correlated with tumor grade and prognosis. Meanwhile, DNMT1 knockdown remarkably enhances ADAMTS9-AS2 expression, inhibiting cell migration in gliomas (Yao et al., 2014).

\section{LncRNA SPRY4-IT1}

SPRY4-IT1, a 708 bp intron-retained lncRNA localized at chromosome 5q31.3, is found to be significantly expressed in breast cancer (Shi Y. et al., 2015), osteosarcoma (Ru et al., 2016) and bladder cancer (Zhao X.L. et al., 2015), and its suppression can inhibit proliferation and induce apoptosis in cancer cells. SPRY4-IT1 was originally reported by Khaitan et al. (2011) to play an important role in the molecular etiology, modulation of cell apoptosis and invasion of human melanoma. Recently, the expression of SPRY4-IT1 is shown to be significantly expressed in glioma tissues and glioma cell lines compared with normal donors (Liu H. et al., 2015). The epithelial-to-mesenchymal transition (EMT), as a relevant molecular event in malignant gliomas, is an essential process in tumor dissemination and metastatic behavior (Kahlert et al., 2013). Liu H. et al. (2015) showed that the knockdown of SPRY4-IT1 by siRNA could suppress the EMT phenotype in glioma cells (U251 and SF295). However, the exact mechanism underlying the role of SPRY4-IT1 in glioma pathology still remains to be elucidated.

\section{LncRNA HULC}

Highly up-regulated in liver cancer has pro-oncogenic activity in many human malignancies, such as B-cell lymphoma (Peng et al., 2016), hepatocellular carcinoma (Huang et al., 2016), and osteosarcoma (Sun et al., 2015). Recently, Zhu's et al. (2016) reported that HULC has important biological function in human gliomas. HULC can promote the angiogenesis, one hallmark of malignant gliomas, by inhibiting the expression of angiogenesisrelated molecule ESM-1 (endothelial cell specific molecule 1). In addition, the $\mathrm{PI} 3 \mathrm{~K} / \mathrm{AKT} / \mathrm{mTOR}$ signaling pathway is involved in the response induced by HULC (Zhu et al., 2016). These intriguing findings will help pave the way for exciting functional studies of HULC in gliomagenesis. 


\section{CONCLUSION AND REMARKS}

Long non-coding RNA-based mechanisms alter cell fate during development, and their dysregulation underscores many human disorders, including gliomas. LncRNAs play indispensable roles in the onset and progression of this malignancy, including the proliferation, metastasis and EMT of glioma cells. Though previously considered "junk sequences" in our genomes, the epigenetic role of lncRNA should promise to be another exciting marker for glioma research and therapy. In addition, extracellular vesicles (EVs), like exosomes, isolated from blood, cerebrospinal fluid (CSF), and other biofluids of GBM patients could offer new insight into cancer biology with both diagnostic and therapeutic implications. These exosomes have been found to harbor gliomaderived specific lncRNAs that are significantly different in cancer patients compared with normal controls (Chistiakov and Chekhonin, 2014). Moreover, exosome-transmitted lncRNAs could promote chemotherapeutic resistance in cancer by acting as a competing endogenous RNA (ceRNA; Qu et al., 2016). They can act as sponges for competitively binding miRNAs through their miRNA-recognizing elements (MREs) and further regulate the expression of miRNAs (Denzler et al., 2014; Yang et al., 2016). Strikingly, these MRE elements implicated in the ceRNA networks are also able to regulate the mRNA expression playing critical roles in tumorigenesis (Guo et al., 2015). Understanding the key roles of "IncRNA-miRNA" and "IncRNA-mRNA" interactions in the pathogenesis of gliomas will lead to the identification of new targets for GBM treatment.

In addition, TMZ, an alkylating agent, is the most widely used and effective first-line chemotherapeutic drug for treating primary and recurrent high-grade gliomas (Messaoudi et al., 2015). TMZ could activate autophagy in tumor cells. Autophagic modulators could lead to either cell survival or cell death, depending on the cellular context, which further affects the therapeutic sensitivity of TMZ in GBM (Yan et al., 2016). Recently, it has been proposed that serving as factors in gene regulation, IncRNAs could control cellular processes such as autophagy in disease conditions (Choudhry et al., 2016). The oncogene lncRNA HNF1A-AS1 could promote tumor growth by sponging tumor-suppressive hsa-miR-30b-5p in hepatocellular carcinoma. Meanwhile, the HNF1A-AS1-miR-30b axis could significantly up-regulate cell autophagy during starvation by enhancing the expression of ATG5, the target of miR-30b (Liu Z. et al., 2016). However, upon energy stress, IncRNA NBR2 (neighbor of BRCA1 gene 2) could promote AMP-activated protein kinase (AMPK) activity through interacting with AMPK, leading to a depressed autophagy response and increased tumor

\section{REFERENCES}

Baldinu, P., Cossu, A., Manca, A., Satta, M. P., Sini, M. C., Palomba, G., et al. (2007). CASC2a gene is down-regulated in endometrial cancer. Anticancer. Res. 27, 235-243.

Baldinu, P., Cossu, A., Manca, A., Satta, M. P., Sini, M. C., Rozzo, C., et al. (2004). Identification of a novel candidate gene, CASC2, in a region of common allelic development (Liu X. et al., 2016). Thus, further investigation of lncRNAs in autophagy regulation would be able to identify novel strategies to enhance the benefits of TMZ chemosensitivity and chemoprotection in the treatment of gliomas.

In the last decade, IncRNAs have been regarded as molecular targets for the treatment of many cancers, including gliomas (Lavorgna et al., 2016). Furthermore, recent advancements in deep sequencing are now providing new tools to functionally annotate disease-associated lncRNAs, facilitating the identification of these new transcripts for cancer therapy (Huarte, 2015; Zheng L.L. et al., 2016). However, their biological effects are easily influenced by many factors, such as delivery strategies to cross the BTB. A better understanding of the real efficacy and mechanisms of lncRNAs, particularly in human patients, represents a matter of great interest for possible clinical application in future. Ma et al. (2016) found that the knockdown of the lncRNA NEAT2 in gliomas could result in the significantly increased permeability of $\mathrm{BTB}$, which might contribute to enhancing potential therapeutic strategies for human gliomas. Meanwhile, the results from Liu's group indicated that the IncRNA TUG1, which is highly expressed in vascular endothelial cells from glioma tissues, could influence BTB permeability via binding to miR-144, further reducing the expression of tight junction proteins in endothelial cells, such as ZO-1, occludin, and claudin-5 (Cai et al., 2015). Thus, extensive work should focus on the role of lncRNAs in BTB permeability, which may represent a useful therapeutic target for human glioma treatment.

\section{AUTHOR CONTRIBUTIONS}

YY, ZX and ZL wrote this review article. LS and ZG designed the study and contributed in manuscript preparation.

\section{FUNDING}

This work was supported by the National Natural Science Foundation of China (No. 81572946), the Changsha Science and Technology Project (No. k1508024-31), and the Clinical and Rehabilitation Research Foundation of Xiangya hospital Beidaweiming.

\section{ACKNOWLEDGMENT}

ZX is right now a Postdoctoral Fellow in Department of Pharmacy, Xiangya Hospital, Central South University.

loss at chromosome 10q26 in human endometrial cancer. Hum. Mutat. 23, 318-326. doi: 10.1002/humu.20015

Barsyte-Lovejoy, D., Lau, S. K., Boutros, P. C., Khosravi, F., Jurisica, I., Andrulis, I. L., et al. (2006). The c-Myc oncogene directly induces the H19 noncoding RNA by allele-specific binding to potentiate tumorigenesis. Cancer Res. 66, 5330-5337. doi: 10.1158/0008-5472.CAN06-0037 
Batista, P. J., and Chang, H. Y. (2013). Long noncoding RNAs: cellular address codes in development and disease. Cell 152, 1298-1307. doi: 10.1016/j.cell.2013. 02.012

Belter, A., Rolle, K., Piwecka, M., Fedoruk-Wyszomirska, A., NaskretBarciszewska, M. Z., and Barciszewski, J. (2016). Inhibition of miR-21 in glioma cells using catalytic nucleic acids. Sci. Rep. 6:24516. doi: 10.1038/srep24516

Berteaux, N., Lottin, S., Monte, D., Pinte, S., Quatannens, B., Coll, J., et al. (2005). H19 mRNA-like noncoding RNA promotes breast cancer cell proliferation through positive control by E2F1. J. Biol. Chem. 280, 29625-29636. doi: 10.1074/ jbc.M504033200

Bian, E. B., Li, J., Xie, Y. S., Zong, G., Li, J., and Zhao, B. (2015). LncRNAs: new players in gliomas, with special emphasis on the interaction of lncRNAs With EZH2. J. Cell. Physiol. 230, 496-503. doi: 10.1002/jcp.24549

Bian, E. B., Ma, C. C., He, X. J., Wang, C., Zong, G., Wang, H. L., et al. (2016). Epigenetic modification of miR-141 regulates SKA2 by an endogenous 'sponge' HOTAIR in glioma. Oncotarget 7, 30610-30625. doi: 10.18632/oncotarget.8895

Cai, B., Song, X. Q., Cai, J. P., and Zhang, S. (2014). HOTAIR: a cancer-related long non-coding RNA. Neoplasma 61, 379-391.

Cai, H., Xue, Y., Wang, P., Wang, Z., Li, Z., Hu, Y., et al. (2015). The long noncoding RNA TUG1 regulates blood-tumor barrier permeability by targeting miR-144. Oncotarget 6, 19759-19779. doi: 10.18632/oncotarget.4331

Cai, J., Zhu, P., Zhang, C., Li, Q., Wang, Z., Li, G., et al. (2016). Detection of ATRX and IDH1-R132H immunohistochemistry in the progression of 211 paired gliomas. Oncotarget 7, 16384-16395. doi: 10.18632/oncotarget.7650

Chen, T., Yang, P., and He, Z. Y. (2016). Long noncoding RNA H19 can predict a poor prognosis and lymph node metastasis: a meta-analysis in human cancer. Minerva Med. 107, 251-258.

Chen, Y., Wu, J. J., Lin, X. B., Bao, Y., Chen, Z. H., Zhang, C. R., et al. (2015). Differential lncRNA expression profiles in recurrent gliomas compared with primary gliomas identified by microarray analysis. Int. J. Clin. Exp. Med. 8, 5033-5043.

Chistiakov, D. A., and Chekhonin, V. P. (2014). Extracellular vesicles shed by glioma cells: pathogenic role and clinical value. Tumour Biol. 35, 8425-8438. doi: 10.1007/s13277-014-2262-9

Choudhry, H., Harris, A. L., and McIntyre, A. (2016). The tumour hypoxia induced non-coding transcriptome. Mol. Aspects Med. 4, 35-53. doi: 10.1016/j.mam. 2016.01.003

Cohen, S. M. (2014). Everything old is new again: (linc)RNAs make proteins! EMBO J. 33, 937-938. doi: 10.1002/embj.201488303

Denzler, R., Agarwal, V., Stefano, J., Bartel, D. P., and Stoffel, M. (2014). Assessing the ceRNA hypothesis with quantitative measurements of miRNA and target abundance. Mol. Cell 54, 766-776. doi: 10.1016/j.molcel.2014.03.045

Derrien, T., Johnson, R., Bussotti, G., Tanzer, A., Djebali, S., Tilgner, H., et al. (2012). The GENCODE v7 catalog of human long noncoding RNAs: analysis of their gene structure, evolution, and expression. Genome Res. 22, 1775-1789. doi: 10.1101/gr.132159.111

Diederichs, S., Bartsch, L., Berkmann, J. C., Frose, K., Heitmann, J., Hoppe, C., et al. (2016). The dark matter of the cancer genome: aberrations in regulatory elements, untranslated regions, splice sites, non-coding RNA and synonymous mutations. EMBO Mol. Med. 8, 442-457. doi: 10.15252/emmm.201506055

Ellis, B. C., Molloy, P. L., and Graham, L. D. (2012). CRNDE: a long non-coding RNA involved in CanceR, neurobiology, and DEvelopment. Front. Genet. 3:270. doi: 10.3389/fgene.2012.00270

Fasanaro, P., Greco, S., Lorenzi, M., Pescatori, M., Brioschi, M., Kulshreshtha, R., et al. (2009). An integrated approach for experimental target identification of hypoxia-induced miR-210. J. Biol. Chem. 284, 35134-35143. doi: 10.1074/jbc. M109.052779

Fatica, A., and Bozzoni, I. (2014). Long non-coding RNAs: new players in cell differentiation and development. Nat. Rev. Genet. 15, 7-21. doi: 10.1038/ nrg3606

Fujimoto, A., Furuta, M., Totoki, Y., Tsunoda, T., Kato, M., Shiraishi, Y., et al. (2016). Whole-genome mutational landscape and characterization of noncoding and structural mutations in liver cancer. Nat. Genet. 48, 500-509. doi: 10.1038/ng. 3547

Furlan, G., and Rougeulle, C. (2016). Function and evolution of the long noncoding RNA circuitry orchestrating X-chromosome inactivation in mammals. Wiley Interdiscip. Rev. RNA 7, 702-722. doi: 10.1002/wrna.1359
Furnari, F. B., Cloughesy, T. F., Cavenee, W. K., and Mischel, P. S. (2015). Heterogeneity of epidermal growth factor receptor signalling networks in glioblastoma. Nat. Rev. Cancer 15, 302-310. doi: 10.1038/nrc3918

Galasso, M., Dama, P., Previati, M., Sandhu, S., Palatini, J., Coppola, V., et al. (2014). A large scale expression study associates uc.283-plus IncRNA with pluripotent stem cells and human glioma. Genome Med. 6, 76. doi: 10.1186/ s13073-014-0076-4

Garcia-Claver, A., Lorente, M., Mur, P., Campos-Martin, Y., Mollejo, M., Velasco, G., et al. (2013). Gene expression changes associated with erlotinib response in glioma cell lines. Eur. J. Cancer 49, 1641-1653. doi: 10.1016/j.ejca. 2013.01.002

Goodrich, L., Panning, B., and Leung, K. N. (2016). Activators and repressors: a balancing act for X-inactivation. Semin. Cell Dev. Biol. 56, 3-8. doi: 10.1016/j. semcdb.2016.05.005

Guo, L. L., Song, C. H., Wang, P., Dai, L. P., Zhang, J. Y., and Wang, K. J. (2015). Competing endogenous RNA networks and gastric cancer. World J. Gastroenterol. 21, 11680-11687. doi: 10.3748/wjg.v21.i41.11680

Han, L., Zhang, K., Shi, Z., Zhang, J., Zhu, J., Zhu, S., et al. (2012). LncRNA pro fi le of glioblastoma reveals the potential role of lncRNAs in contributing to glioblastoma pathogenesis. Int. J. Oncol. 40, 2004-2012. doi: 10.3892/ijo.2012. 1413

Han, Y., Wu, Z., Wu, T., Huang, Y., Cheng, Z., Li, X., et al. (2016a). Tumorsuppressive function of long noncoding RNA MALAT1 in glioma cells by downregulation of MMP2 and inactivation of ERK/MAPK signaling. Cell Death Dis. 7, e2123. doi: 10.1038/cddis.2015.407

Han, Y., Zhou, L., Wu, T., Huang, Y., Cheng, Z., Li, X., et al. (2016b). Downregulation of IncRNA-MALAT1 affects proliferation and the expression of stemness markers in glioma stem cell line SHG139S. Cell. Mol. Neurobiol. 36, 1097-1107. doi: 10.1007/s10571-015-0303-6

Harmalkar, M., Upraity, S., Kazi, S., and Shirsat, N. V. (2015). Tamoxifen-induced cell death of malignant glioma cells is brought about by oxidative-stressmediated alterations in the expression of BCL2 family members and is enhanced on miR-21 inhibition. J. Mol. Neurosci. 57, 197-202. doi: 10.1007/s12031-015$0602-\mathrm{x}$

He, C., Jiang, B., Ma, J., and Li, Q. (2016). Aberrant NEAT1 expression is associated with clinical outcome in high grade glioma patients. APMIS 124, 169-174. doi: 10.1111/apm.12480

He, X., Liu, Z., Su, J., Yang, J., Yin, D., Han, L., et al. (2016). Low expression of long noncoding RNA CASC2 indicates a poor prognosis and regulates cell proliferation in non-small cell lung cancer. Tumour Biol. 37, 9503-9510. doi: 10.1007/s13277-016-4787-6

Hendricks, B. K., Cohen-Gadol, A. A., and Miller, J. C. (2015). Novel delivery methods bypassing the blood-brain and blood-tumor barriers. Neurosurg. Focus 38:E10. doi: 10.3171/2015.1.FOCUS14767

Ho, Y. Y., Evans, D. M., Montgomery, G. W., Henders, A. K., Kemp, J. P., Timpson, N. J., et al. (2016). Common genetic variants influence whorls in fingerprint patterns. J. Invest. Dermatol. 136, 859-862. doi: 10.1016/j.jid.2015.10.062

Huang, J., Yang, J., Lei, Y., Gao, H., Wei, T., Luo, L., et al. (2016). An ANCCA/PRO2000-miR-520a-E2F2 regulatory loop as a driving force for the development of hepatocellular carcinoma. Oncogenesis 5, e229. doi: 10.1038/ oncsis. 2016.22

Huarte, M. (2015). The emerging role of IncRNAs in cancer. Nat. Med. 21, 1253-1261. doi: 10.1038/nm.3981

Jiang, X., Yan, Y., Hu, M., Chen, X., Wang, Y., Dai, Y., et al. (2016). Increased level of H19 long noncoding RNA promotes invasion, angiogenesis, and stemness of glioblastoma cells. J. Neurosurg. 124, 129-136. doi: 10.3171/2014.12.JNS1426

Kahlert, U. D., Nikkhah, G., and Maciaczyk, J. (2013). Epithelial-to-mesenchymal (-like) transition as a relevant molecular event in malignant gliomas. Cancer Lett. 331, 131-138. doi: 10.1016/j.canlet.2012.12.010

Ke, J., Yao, Y. L., Zheng, J., Wang, P., Liu, Y. H., Ma, J., et al. (2015). Knockdown of long non-coding RNA HOTAIR inhibits malignant biological behaviors of human glioma cells via modulation of miR-326. Oncotarget 6, 21934-21949. doi: 10.18632 /oncotarget.4290

Khaitan, D., Dinger, M. E., Mazar, J., Crawford, J., Smith, M. A., Mattick, J. S., et al. (2011). The melanoma-upregulated long noncoding RNA SPRY4-IT1 modulates apoptosis and invasion. Cancer Res. 71, 3852-3862. doi: 10.1158/ 0008-5472.CAN-10-4460 
Kiang, K. M., Zhang, X. Q., and Leung, G. K. (2015). Long non-coding RNAs: the key players in glioma pathogenesis. Cancers 7, 1406-1424. doi: 10.3390/ cancers7030843

Kino, T., Hurt, D. E., Ichijo, T., Nader, N., and Chrousos, G. P. (2010). Noncoding RNA gas5 is a growth arrest- and starvation-associated repressor of the glucocorticoid receptor. Sci. Signal. 3, ra8. doi: 10.1126/scisignal.2000568

Kitambi, S. S., Toledo, E. M., Usoskin, D., Wee, S., Harisankar, A., Svensson, R., et al. (2014). Vulnerability of glioblastoma cells to catastrophic vacuolization and death induced by a small molecule. Cell 157, 313-328. doi: 10.1016/j.cell. 2014.02.021

Kraus, T. F., Greiner, A., Guibourt, V., Lisec, K., and Kretzschmar, H. A. (2015). Identification of stably expressed lncRNAs as valid endogenous controls for profiling of human glioma. J. Cancer 6, 111-119. doi: 10.7150/jca. 10867

Lathia, J. D., Mack, S. C., Mulkearns-Hubert, E. E., Valentim, C. L., and Rich, J. N. (2015). Cancer stem cells in glioblastoma. Genes Dev. 29, 1203-1217. doi: $10.1101 / \operatorname{gad} .261982 .115$

Lavorgna, G., Vago, R., Sarmini, M., Montorsi, F., Salonia, A., and Bellone, M. (2016). Long non-coding RNAs as novel therapeutic targets in cancer. Pharmacol. Res. 110, 131-138. doi: 10.1016/j.phrs.2016.05.018

Li, C., Lei, B., Huang, S., Zheng, M., Liu, Z., Li, Z., et al. (2015). H19 derived microRNA-675 regulates cell proliferation and migration through CDK6 in glioma. Am. J. Transl. Res. 7, 1747-1764.

Li, J., Zhang, M., An, G., and Ma, Q. (2016). LncRNA TUG1 acts as a tumor suppressor in human glioma by promoting cell apoptosis. Exp. Biol. Med. 241, 644-649. doi: 10.1177/1535370215622708

Li, R., Qian, J., Wang, Y. Y., Zhang, J. X., and You, Y. P. (2014). Long noncoding RNA profiles reveal three molecular subtypes in glioma. CNS Neurosci. Ther. 20, 339-343. doi: 10.1111/cns.12220

Li, W., Jiang, P., Sun, X., Xu, S., Ma, X., and Zhan, R. (2016). Suppressing H19 modulates tumorigenicity and stemness in U251 and U87MG glioma cells. Cell. Mol. Neurobiol. 36, 1219-1227. doi: 10.1007/s10571-0150320-5

Li, Y., Wang, H., Sun, T., Chen, J., Guo, L., Shen, H., et al. (2015). Biological characteristics of a new human glioma cell line transformed into A2B5(+) stem cells. Mol. Cancer 14, 75. doi: 10.1186/s12943-015-0343-z

Liu, H., Lv, Z., and Guo, E. (2015). Knockdown of long noncoding RNA SPRY4-IT1 suppresses glioma cell proliferation, metastasis and epithelial- mesenchymal transition. Int. J. Clin. Exp. Pathol. 8, 9140-9146.

Liu, Q., Sun, S., Yu, W., Jiang, J., Zhuo, F., Qiu, G., et al. (2015). Altered expression of long non-coding RNAs during genotoxic stress-induced cell death in human glioma cells. J. Neurooncol. 122, 283-292. doi: 10.1007/s11060-015-1718-0

Liu, X., Xiao, Z. D., Han, L., Zhang, J., Lee, S. W., Wang, W., et al. (2016). LncRNA NBR2 engages a metabolic checkpoint by regulating AMPK under energy stress. Nat. Cell Biol. 18, 431-442. doi: 10.1038/ncb3328

Liu, Z., Wei, X., Zhang, A., Li, C., Bai, J., and Dong, J. (2016). Long non-coding RNA HNF1A-AS1 functioned as an oncogene and autophagy promoter in hepatocellular carcinoma through sponging hsa-miR-30b-5p. Biochem. Biophys. Res. Commun. 473, 1268-1275. doi: 10.1016/j.bbrc.2016.04.054

Ma, J., Wang, P., Yao, Y., Liu, Y., Li, Z., Liu, X., et al. (2016). Knockdown of long non-coding RNA MALAT1 increases the blood-tumor barrier permeability by up-regulating miR-140. Biochim. Biophys. Acta 1859, 324-338. doi: 10.1016/j. bbagrm.2015.11.008

Maduro, C., de Hoon, B., and Gribnau, J. (2016). Fitting the puzzle pieces: the bigger picture of XCI. Trends Biochem. Sci. 41, 138-147. doi: 10.1016/j.tibs.2015. 12.003

Mercer, T. R., and Mattick, J. S. (2013). Structure and function of long noncoding RNAs in epigenetic regulation. Nat. Struct. Mol. Biol. 20, 300-307. doi: 10.1038/ nsmb. 2480

Messaoudi, K., Clavreul, A., and Lagarce, F. (2015). Toward an effective strategy in glioblastoma treatment. Part I: resistance mechanisms and strategies to overcome resistance of glioblastoma to temozolomide. Drug Discov. Today 20, 899-905. doi: 10.1016/j.drudis.2015.02.011

Naganuma, T., and Hirose, T. (2013). Paraspeckle formation during the biogenesis of long non-coding RNAs. RNA Biol. 10, 456-461. doi: 10.4161/rna.23547

Ostrom, Q. T., Bauchet, L., Davis, F. G., Deltour, I., Fisher, J. L., Langer, C. E., et al. (2014). The epidemiology of glioma in adults: a "state of the science" review. Neuro Oncol. 16, 896-913. doi: 10.1093/neuonc/nou087
Pastori, C., Daniel, M., Penas, C., Volmar, C. H., Johnstone, A. L., Brothers, S. P., et al. (2014). BET bromodomain proteins are required for glioblastoma cell proliferation. Epigenetics 9, 611-620. doi: 10.4161/epi.27906

Pastori, C., Kapranov, P., Penas, C., Peschansky, V., Volmar, C. H., Sarkaria, J. N., et al. (2015). The Bromodomain protein BRD4 controls HOTAIR, a long noncoding RNA essential for glioblastoma proliferation. Proc. Natl. Acad. Sci. U.S.A. 112, 8326-8331. doi: 10.1073/pnas.1424220112

Penaranda Fajardo, N. M., Meijer, C., and Kruyt, F. A. (2016). The endoplasmic reticulum stress/unfolded protein response in gliomagenesis, tumor progression and as a therapeutic target in glioblastoma. Biochem. Pharmacol. 118, 1-8. doi: 10.1016/j.bcp.2016.04.008

Peng, W., Wu, J., and Feng, J. (2016). Long noncoding RNA HULC predicts poor clinical outcome and represents pro-oncogenic activity in diffuse large B-cell lymphoma. Biomed. Pharmacother. 79, 188-193. doi: 10.1016/j.biopha.2016. 02.032

Pickard, M. R., and Williams, G. T. (2015). Molecular and cellular mechanisms of action of tumour suppressor GAS5 LncRNA. Genes 6, 484-499. doi: 10.3390/ genes6030484

Qu, L., Ding, J., Chen, C., Wu, Z. J., Liu, B., Gao, Y., et al. (2016). Exosometransmitted lncARSR promotes sunitinib resistance in renal cancer by acting as a competing endogenous RNA. Cancer Cell 29, 653-668. doi: 10.1016/j.ccell. 2016.03.004

Quinn, J. J., and Chang, H. Y. (2016). Unique features of long non-coding RNA biogenesis and function. Nat. Rev. Genet. 17, 47-62. doi: 10.1038/nrg. 2015.10

Rader, J., Russell, M. R., Hart, L. S., Nakazawa, M. S., Belcastro, L. T., Martinez, D., et al. (2013). Dual CDK4/CDK6 inhibition induces cell-cycle arrest and senescence in neuroblastoma. Clin. Cancer Res. 19, 6173-6182. doi: 10.1158/ 1078-0432.CCR-13-1675

Ramos, A. D., Attenello, F. J., and Lim, D. A. (2016). Uncovering the roles of long noncoding RNAs in neural development and glioma progression. Neurosci. Lett. 625, 70-79. doi: 10.1016/j.neulet.2015.12.025,

Rohrmann, S., Linseisen, J., Becker, S., Allen, N., Schlehofer, B., Overvad, K., et al. (2011). Concentrations of IGF-I and IGFBP-3 and brain tumor risk in the European Prospective Investigation into Cancer and Nutrition. Cancer Epidemiol. Biomarkers. Prev. 20, 2174-2182. doi: 10.1158/1055-9965.EPI-110179

Ru, N., Liang, J., Zhang, F., Wu, W., Wang, F., Liu, X., et al. (2016). SPRY4 intronic transcript 1 promotes epithelial-mesenchymal transition through association with snail1 in osteosarcoma. DNA Cell Biol. 35, 290-295. doi: 10.1089/dna.2016. 3226

Ruiz-Orera, J., Messeguer, X., Subirana, J. A., and Alba, M. M. (2014). Long noncoding RNAs as a source of new peptides. Elife 3:e03523. doi: 10.7554/eLife. 03523

Sahu, A., Singhal, U., and Chinnaiyan, A. M. (2015). Long noncoding RNAs in cancer: from function to translation. Trends Cancer 1, 93-109.

Sarma, K., Cifuentes-Rojas, C., Ergun, A., Del Rosario, A., Jeon, Y., White, F., et al. (2014). ATRX directs binding of PRC2 to Xist RNA and Polycomb targets. Cell 159, 869-883. doi: 10.1016/j.cell.2014.10.019

Schmitt, A. M., and Chang, H. Y. (2016). Long noncoding RNAs in cancer pathways. Cancer Cell 29, 452-463. doi: 10.1016/j.ccell.2016.03.010

Schmitz, S. U., Grote, P., and Herrmann, B. G. (2016). Mechanisms of long noncoding RNA function in development and disease. Cell Mol. Life Sci. 73, 2491-2509. doi: 10.1007/s00018-016-2174-5

Sherr, C. J., Beach, D., and Shapiro, G. I. (2016). Targeting CDK4 and CDK6: from discovery to therapy. Cancer Discov. 6, 353-367. doi: 10.1158/2159-8290.CD15-0894

Shi, X., Sun, M., Liu, H., Yao, Y., Kong, R., Chen, F., et al. (2015). A critical role for the long non-coding RNA GAS5 in proliferation and apoptosis in nonsmall-cell lung cancer. Mol. Carcinog. 54(Suppl. 1), E1-E12. doi: 10.1002/mc. 22120

Shi, Y., Li, J., Liu, Y., Ding, J., Fan, Y., Tian, Y., et al. (2015). The long noncoding RNA SPRY4-IT1 increases the proliferation of human breast cancer cells by upregulating ZNF703 expression. Mol Cancer 14, 51. doi: 10.1186/s12943-0150318-0

Shi, Y., Wang, Y., Luan, W., Wang, P., Tao, T., Zhang, J., et al. (2014). Long noncoding RNA H19 promotes glioma cell invasion by deriving miR-675. PLoS ONE 9:e86295. doi: 10.1371/journal.pone.0086295 
Simon, M. D., Pinter, S. F., Fang, R., Sarma, K., Rutenberg-Schoenberg, M., Bowman, S. K., et al. (2013). High-resolution Xist binding maps reveal twostep spreading during X-chromosome inactivation. Nature 504, 465-469. doi: 10.1038/nature12719

Stetson, L. C., Dazard, J. E., and Barnholtz-Sloan, J. S. (2016). Protein markers predict survival in glioma patients. Mol. Cell. Proteomics 15, 2356-2365. doi: 10.1074/mcp.M116.060657

Sun, X. H., Yang, L. B., Geng, X. L., Wang, R., and Zhang, Z. C. (2015). Increased expression of lncRNA HULC indicates a poor prognosis and promotes cell metastasis in osteosarcoma. Int. J. Clin. Exp. Pathol. 8, 2994-3000.

Tan, J., Qiu, K., Li, M., and Liang, Y. (2015). Double-negative feedback loop between long non-coding RNA TUG1 and miR-145 promotes epithelial to mesenchymal transition and radioresistance in human bladder cancer cells. FEBS Lett. 589(20 Pt B), 3175-3181. doi: 10.1016/j.febslet.2015.08.020

Tantai, J., Hu, D., Yang, Y., and Geng, J. (2015). Combined identification of long non-coding RNA XIST and HIF1A-AS1 in serum as an effective screening for non-small cell lung cancer. Int. J. Clin. Exp. Pathol. 8, 7887-7895.

Trojan, L. A., Kopinski, P., Mazurek, A., Chyczewski, L., Ly, A., Jarocki, P., et al. (2003). IGF-I triple helix gene therapy of rat and human gliomas. Rocz. Akad. Med. Bialymst. 48, 18-27.

Tsai, M. C., Manor, O., Wan, Y., Mosammaparast, N., Wang, J. K., Lan, F., et al. (2010). Long noncoding RNA as modular scaffold of histone modification complexes. Science 329, 689-693. doi: 10.1126/science.1192002

van Vlerken, L. E., Kiefer, C. M., Morehouse, C., Li, Y., Groves, C., Wilson, S. D., et al. (2013). EZH2 is required for breast and pancreatic cancer stem cell maintenance and can be used as a functional cancer stem cell reporter. Stem Cells Transl. Med. 2, 43-52. doi: 10.5966/sctm.2012-0036

Wakamatsu, A., Kimura, K., Yamamoto, J., Nishikawa, T., Nomura, N., Sugano, S., et al. (2009). Identification and functional analyses of 11,769 full-length human cDNAs focused on alternative splicing. DNA Res. 16, 371-383. doi: 10.1093/ dnares/dsp022

Walsh, S., Pospiech, E., and Branicki, W. (2016). Hot on the trail of genes that shape our fingerprints. J. Invest. Dermatol. 136, 740-742. doi: 10.1016/j.jid.2015. 12.044

Wang, J., Ma, R., Ma, W., Chen, J., Yang, J., Xi, Y., et al. (2016). LncDisease: a sequence based bioinformatics tool for predicting lncRNA-disease associations. Nucleic Acids Res. 44, e90. doi: 10.1093/nar/gkw093

Wang, P., Liu, Y. H., Yao, Y. L., Li, Z., Li, Z. Q., Ma, J., et al. (2015). Long noncoding RNA CASC2 suppresses malignancy in human gliomas by miR-21. Cell. Signal. 27, 275-282. doi: 10.1016/j.cellsig.2014.11.011

Wang, P. F., Liu, N., Song, H. W., Yao, K., Jiang, T., Li, S. W., et al. (2016). IDH-1R132H mutation status in diffuse glioma patients: implications for classification. Oncotarget 7, 31393-31400. doi: 10.18632/oncotarget.8918

Wang, Y., Wang, Y., Li, J., Zhang, Y., Yin, H., and Han, B. (2015). CRNDE, a longnoncoding RNA, promotes glioma cell growth and invasion through mTOR signaling. Cancer Lett. 367, 122-128. doi: 10.1016/j.canlet.2015.03.027

Wang, Z., Jensen, M. A., and Zenklusen, J. C. (2016). A practical guide to The Cancer Genome Atlas (TCGA). Methods Mol. Biol. 1418, 111-141. doi: 10.1007/ 978-1-4939-3578-9_6

Watkins, S., and Sontheimer, H. (2012). Unique biology of gliomas: challenges and opportunities. Trends Neurosci. 35, 546-556. doi: 10.1016/j.tins.2012.05.001

Wei, Y., and Niu, B. (2015). Role of MALAT1 as a prognostic factor for survival in various cancers: a systematic review of the literature with meta-analysis. Dis. Markers 2015:164635. doi: 10.1155/2015/164635

Wick, W., Weller, M., van den Bent, M., Sanson, M., Weiler, M., von Deimling, A., et al. (2014). MGMT testing-the challenges for biomarker-based glioma treatment. Nat. Rev. Neurol. 10, 372-385. doi: 10.1038/nrneurol.2014.100

Wu, Y., Zhang, L., Wang, Y., Li, H., Ren, X., Wei, F., et al. (2014). Long noncoding RNA HOTAIR involvement in cancer. Tumour Biol. 35, 9531-9538. doi: 10. 1007/s13277-014-2523-7

Xiang, J., Guo, S., Jiang, S., Xu, Y., Li, J., Li, L., et al. (2016). Silencing of long noncoding RNA MALAT1 promotes apoptosis of glioma cells. J. Korean Med. Sci. 31, 688-694. doi: 10.3346/jkms.2016.31.5.688

Yan, Y., Xu, Z., Dai, S., Qian, L., Sun, L., and Gong, Z. (2016). Targeting autophagy to sensitive glioma to temozolomide treatment. J. Exp. Clin. Cancer Res. 35, 23. doi: 10.1186/s13046-016-0303-5

Yan, Y., Zhang, L., Jiang, Y., Xu, T., Mei, Q., Wang, H., et al. (2015). LncRNA and mRNA interaction study based on transcriptome profiles reveals potential core genes in the pathogenesis of human glioblastoma multiforme. J. Cancer Res. Clin. Oncol. 141, 827-838. doi: 10.1007/s00432-014-1861-6

Yang, C., Wu, D., Gao, L., Liu, X., Jin, Y., Wang, D., et al. (2016). Competing endogenous RNA networks in human cancer: hypothesis, validation, and perspectives. Oncotarget 7, 13479-13490. doi: 10.18632/oncotarget.7266

Yao, J., Zhou, B., Zhang, J., Geng, P., Liu, K., Zhu, Y., et al. (2014). A new tumor suppressor LncRNA ADAMTS9-AS2 is regulated by DNMT1 and inhibits migration of glioma cells. Tumour Biol. 35, 7935-7944. doi: 10.1007/s13277014-1949-2

Yao, Y., Ma, J., Xue, Y., Wang, P., Li, Z., Liu, J., et al. (2015). Knockdown of long non-coding RNA XIST exerts tumor-suppressive functions in human glioblastoma stem cells by up-regulating miR-152. Cancer Lett. 359, 75-86. doi: 10.1016/j.canlet.2014.12.051

Yildirim, E., Kirby, J. E., Brown, D. E., Mercier, F. E., Sadreyev, R. I., Scadden, D. T., et al. (2013). Xist RNA is a potent suppressor of hematologic cancer in mice. Cell 152, 727-742. doi: 10.1016/j.cell.2013.01.034

Yin, D., He, X., Zhang, E., Kong, R., De, W., and Zhang, Z. (2014). Long noncoding RNA GAS5 affects cell proliferation and predicts a poor prognosis in patients with colorectal cancer. Med. Oncol. 31, 253. doi: 10.1007/s12032-014-0253-8

Yin, Y., Qiu, S., and Peng, Y. (2016). Functional roles of enhancer of zeste homolog 2 in gliomas. Gene 576(1 Pt 2), 189-194. doi: 10.1016/j.gene.2015.09.080

Yoon, J. H., Abdelmohsen, K., Kim, J., Yang, X., Martindale, J. L., TominagaYamanaka, K., et al. (2013). Scaffold function of long non-coding RNA HOTAIR in protein ubiquitination. Nat. Commun. 4, 2939. doi: 10.1038/ncomms3939

Young, T. L., Matsuda, T., and Cepko, C. L. (2005). The noncoding RNA taurine upregulated gene 1 is required for differentiation of the murine retina. Curr. Biol. 15, 501-512. doi: 10.1016/j.cub.2005.02.027

Yu, B., and Shan, G. (2016). Functions of long noncoding RNAs in the nucleus. Nucleus 7, 155-166. doi: 10.1080/19491034.2016.1179408

Zhang, C., and Peng, G. (2015). Non-coding RNAs: an emerging player in DNA damage response. Mutat. Res. Rev. Mutat. Res. 763, 202-211. doi: 10.1016/j. mrrev.2014.11.003

Zhang, E. B., Yin, D. D., Sun, M., Kong, R., Liu, X. H., You, L. H., et al. (2014). P53-regulated long non-coding RNA TUG1 affects cell proliferation in human non-small cell lung cancer, partly through epigenetically regulating HOXB7 expression. Cell Death Dis. 5, e1243. doi: 10.1038/cddis.2014.201

Zhang, J. X., Han, L., Bao, Z. S., Wang, Y. Y., Chen, L. Y., Yan, W., et al. (2013). HOTAIR, a cell cycle-associated long noncoding RNA and a strong predictor of survival, is preferentially expressed in classical and mesenchymal glioma. Neuro Oncol. 15, 1595-1603. doi: 10.1093/neuonc/not131

Zhang, K., Sun, X., Zhou, X., Han, L., Chen, L., Shi, Z., et al. (2015). Long noncoding RNA HOTAIR promotes glioblastoma cell cycle progression in an EZH2 dependent manner. Oncotarget 6, 537-546.

Zhang, X., Sun, S., Pu, J. K., Tsang, A. C., Lee, D., Man, V. O., et al. (2012). Long non-coding RNA expression profiles predict clinical phenotypes in glioma. Neurobiol. Dis. 48, 1-8. doi: 10.1016/j.nbd.2012.06.004

Zhang, X. Q., Kiang, K. M., Wang, Y. C., Pu, J. K., Ho, A., Cheng, S. Y., et al. (2015). IDH1 mutation-associated long non-coding RNA expression profile changes in glioma. J. Neurooncol. 125, 253-263. doi: 10.1007/s11060-015-1916-9

Zhang, X. Q., Sun, S., Lam, K. F., Kiang, K. M., Pu, J. K., Ho, A. S., et al. (2013). A long non-coding RNA signature in glioblastoma multiforme predicts survival. Neurobiol. Dis. 58, 123-131. doi: 10.1016/j.nbd.2013.05.011

Zhang, Z., Zhu, Z., Watabe, K., Zhang, X., Bai, C., Xu, M., et al. (2013). Negative regulation of IncRNA GAS5 by miR-21. Cell Death Differ. 20, 1558-1568. doi: 10.1038/cdd.2013.110

Zhao, H., Sheng, G., Wang, J., Wang, M., Bunkoczi, G., Gong, W., et al. (2014). Crystal structure of the RNA-guided immune surveillance Cascade complex in Escherichia coli. Nature 515, 147-150. doi: 10.1038/nature13733

Zhao, X., Wang, P., Liu, J., Zheng, J., Liu, Y., Chen, J., et al. (2015). Gas5 exerts tumor-suppressive functions in human glioma cells by targeting miR-222. Mol. Ther. 23, 1899-1911. doi: 10.1038/mt.2015.170

Zhao, X. L., Zhao, Z. H., Xu, W. C., Hou, J. Q., and Du, X. Y. (2015). Increased expression of SPRY4-IT1 predicts poor prognosis and promotes tumor growth and metastasis in bladder cancer. Int. J. Clin. Exp. Pathol. 8, 1954-1960.

Zhen, L., Yun-Hui, L., Hong-Yu, D., Jun, M., and Yi-Long, Y. (2016). Long noncoding RNA NEAT1 promotes glioma pathogenesis by regulating miR449b-5p/c-Met axis. Tumour Biol. 37, 673-683. doi: 10.1007/s13277-015$3843-\mathrm{y}$ 
Zheng, J., Li, X. D., Wang, P., Liu, X. B., Xue, Y. X., Hu, Y., et al. (2015). CRNDE affects the malignant biological characteristics of human glioma stem cells by negatively regulating miR-186. Oncotarget 6, 25339-25355. doi: 10.18632/ oncotarget. 4509

Zheng, J., Liu, X., Wang, P., Xue, Y., Ma, J., Qu, C., et al. (2016). CRNDE promotes malignant progression of glioma by attenuating miR384/PIWIL4/STAT3 axis. Mol. Ther. 24, 1199-1215. doi: 10.1038/mt. 2016.71

Zheng, L. L., Li, J. H., Wu, J., Sun, W. J., Liu, S., Wang, Z. L., et al. (2016). deepBase v2.0: identification, expression, evolution and function of small RNAs, LncRNAs and circular RNAs from deep-sequencing data. Nucleic Acids Res. 44, D196-D202. doi: 10.1093/nar/gkv1273

Zhou, X., Ren, Y., Zhang, J., Zhang, C., Zhang, K., Han, L., et al. (2015). HOTAIR is a therapeutic target in glioblastoma. Oncotarget 6, 8353-8365. doi: 10.18632/ oncotarget. 3229

Zhu, Y., Zhang, X., Qi, L., Cai, Y., Yang, P., Xuan, G., et al. (2016). HULC long noncoding RNA silencing suppresses angiogenesis by regulating ESM-1 via the PI3K/Akt/mTOR signaling pathway in human gliomas. Oncotarget 7, 14429-14440. doi: 10.18632/oncotarget.7418

Zhuang, L. K., Yang, Y. T., Ma, X., Han, B., Wang, Z. S., Zhao, Q. Y., et al. (2016). MicroRNA-92b promotes hepatocellular carcinoma progression by targeting Smad7 and is mediated by long non-coding RNA XIST. Cell Death Dis. 7, e2203. doi: $10.1038 /$ cddis. 2016.100

Conflict of Interest Statement: The authors declare that the research was conducted in the absence of any commercial or financial relationships that could be construed as a potential conflict of interest.

Copyright (c) 2017 Yan, Xu, Li, Sun and Gong. This is an open-access article distributed under the terms of the Creative Commons Attribution License (CC BY). The use, distribution or reproduction in other forums is permitted, provided the original author(s) or licensor are credited and that the original publication in this journal is cited, in accordance with accepted academic practice. No use, distribution or reproduction is permitted which does not comply with these terms. 